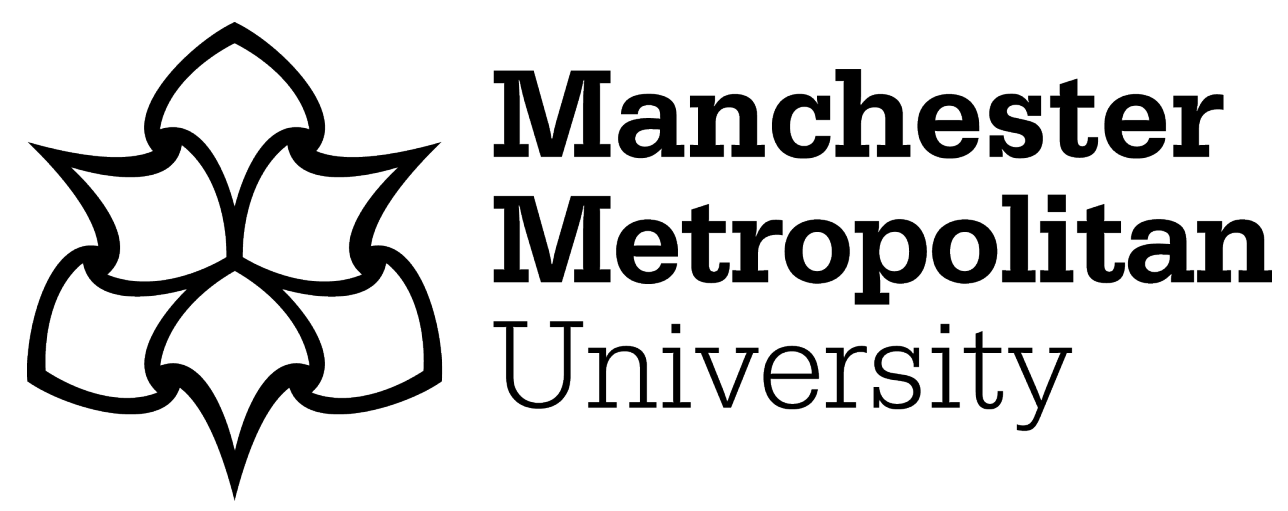

Andreoni, Valeria (2020) Sharing Economy: Risks and Opportunities in a Framework of SDGs. In: Sustainable Cities and Communities. Encyclopedia of the UN Sustainable Development Goals . Springer. ISBN 978-3-31995717-3 (In Press)

Downloaded from: https://e-space.mmu.ac.uk/622099/

Version: Accepted Version

Publisher: Springer

Please cite the published version 


\section{Sharing Economy: Risks and Opportunities in a Framework of SDGs Valeria Andreoni}

Manchester Metropolitan University Business School, All Saints Campus, Oxford Road, Manchester M15 6BH, UK Email: andreoni.valeria@gmail.com

\section{Synonyms}

Collaboration, Access, Provision

\section{Definition}

Sharing economy is defined by a large set of for profit and not-for profit activities developed alongside the expansion of information technologies. Based on the idea of temporary access rather than ownership the sharing economy proposes an alternative consumption model based on the shared use of private resources. In recent years, large academic and political debates have been devoted to investigate the contributions that sharing activities could provide to the transition toward a more sustainable future.

\section{Main text}

\section{Introduction}

The rapid expansion of information technologies and the related availability of internet connection is creating new forms of collaborations across developed and developing countries. The sharing economy, including a large set of activities based on the use of digital platforms and peer-to-peer relationships, is an example of that. Developed alongside the growth of on-line connections and fueled by the global financial crisis of 2008 , the sharing economy has been proposed as an alternative consumption model based on the shared use of private resources. Due to its potential to create new business opportunities and to satisfy consumption needs outside the traditional market system, the sharing economy has attracted significant global attention. In spite of the large academic and political debate, however, a clear definition is still missing and different opinions exist in relation to the possible impacts generated on economy, environment and society. Based on two main characterising elements, namely: the use of information technologies and temporary access rather than ownership, the sharing economy is usually described as an umbrella for a wide range of profit and non-profit activities including the provisions of goods and services and financial support (Acquier et al., 2017; Schor, 2014, Sudararajan, 2016). In Table 1, an overview of some of the main sharing economy' activities are reported.

Table 1. Examples of sharing economy activities

\begin{tabular}{ll}
\hline Sharing Activities & \\
\hline Transport: Related to the provision of & Examples includes: Zipcar, Uber, car2go, \\
transport services taking place by & BlaBlaCar, GoCarShare, GoGet, CarNextDoor, \\
sharing cars, transports or by the & GoCatch, Zazcar, Locomute \\
$\begin{array}{l}\text { development of specific "on demand" } \\
\text { services. }\end{array}$ &
\end{tabular}


$\begin{array}{ll}\text { Property: Related to the provision of } & \text { Examples includes: Airbnb, Noirbnb, } \\ \text { short time accommodation. It } & \text { Couchsurfing, GuestToGuest, Fairbnb }\end{array}$ generally relates to the use of spare rooms in private houses.

Good and Services: Related to the provision of large variety of goods and services. It can take place both in a for-profit or non-profit context.

Financial support: Related to the provision of credits or financial investments taking place in a system running outside the traditional banking structure
Examples includes: Deliveroo, EatWith, UberEATS, JustEat, foodpanda, hungryhouse, NeighborGoods, Freegle, Freecycle, TaskRabbit, Needto.com, Ayoudo, Timebanking

Examples includes: Kickstarter, GoFundMe, Indiegogo, CircleUp

Ranging between transport services, shared accommodation, crowdfunding initiatives and the provision of goods and services, both within and outside the market system, the sharing economy is difficult to define. Dalberg $(2016$, p. 2) for example, defined the sharing economy as "sharing assets - physical, financial and/or human capital, between many without transferring ownership, via a digital platform to create value for at least two parties" and Mohlmann (2015, p. 193) classify into sharing economy all the activities where "participants conduct sharing activities in the form of renting, lending, trading, bartering and swapping of goods, services, transportation solutions, space or money". Matzler et al. (2015), on the contrary, define the sharing economy according to the main activities characterising the interactions, namely: (i) a product-service system based on private ownerships and shared use of products and services (e.g. Airbnb, Uber, Zipcar); (ii) a redistribution system, characterised by a monetary or non-monetary exchange of products (e.g. NeighborGoods, Freegle, Freecycle); (iii) a collaborative lifestyles environment in which people share space, abilities and time (e.g. Kickstarter, TaskRabbit, Timebaning). The lack of a clear definition and the inclusion of a large set activities, based on a wide range of business models, makes it difficult to estimate the possible impacts that sharing activities can generate on economy, society and environment. From a theoretical perspective, sharing economy has been described as a possible solution of the instabilities generated by the traditional market regulated exchanges. In particular, the sharing economy has been framed as a system able to contribute to a transition toward a more sustainable future (Botsman and Rogers, 2010). The idea of collaborative consumption, based on access over ownership, and the possibility to establish socio-economic relationships taking place outside the traditional business environment, has highlighted the possibility of a consumption model able to reduce the impacts on environment and to increase socio-economic opportunities across members of society. Within this context, the sharing economy seems to align with many of the objectives established by the Sustainable Development Goals (SDGs). Oriented to reduce poverty and inequalities by respecting the environmental limits of the planet, the SDGs have been established to guide the policies of developed and developing countries. In the next sections, the main positive impacts of sharing activities are described in relation to the SDGs. In section 3, the main risks, limits and constraints generated the by present structure of the sharing applications are analysed both in relation to developed and developing countries. Section 4 concludes. 


\section{Sharing economy: benefits and potentials in a context of SDGs}

As reported above, the sharing economy is potentially offering a large set of socioeconomic and environmental benefits. A consumption model based on access rather than ownerships and the development of new forms of businesses based on collaborations and alternative market systems can contribute to increase the efficient allocation of resources and to reduce poverty and inequality. In particular, the possible impacts generated by sharing practices can be described according to the main economic, social and environmental implications:

- Economic impacts: From an economic point of view, the sharing economy has the potential to introduce new business models, to stimulate economic growth and to generate employment. The development of activities ranging across hospitality, transport, good and service provision and financial support can contribute to diversify the economic panorama and to generate additional income across different levels of society. In particular, the following economic impacts can be identified:

○ To encourage small and local enterprise: The development of activities taking place outside the traditional market mechanisms is creating business opportunities for small and local enterprise. The creation of a specific market that change the use of privately-owned resources (from private consumption to shared use) has the potential to empower individuals and to provide income and business opportunities outside large corporation and centralised institutions (Benkler, 2017; Munoz and Cohen, 2017).

- To promote alternative source of funding: The generation of additional income, the community support provided by sharing activities and the development of investment provisions based on the use of on-line platforms (such as the crowdfunding initiatives) is providing financial support outside the traditional banking and credit system (Stephani, 2015).

- To reduce income disparities: The generation of additional income, the creation of new business opportunities and the provision of financial support can contribute to reduce inequalities in income generation and distribution (Frenken and Schor, 2017)

○ To generate working opportunities and employment: The sharing economy has been framed as a provider of flexible employment opportunities, based on short term contracts, freelance work and independent working supply (Horpedahl, 2015). The possibility to convert a privately-owned assets and skills into a marketable goods can provide working opportunities particularly for those who would previously have been unemployed

- Tax collection: The generation of business activities and the related income generation can provide the financial base for the collection of additional taxes (Murillo et al., 2017; Kasprowicz, 2016)

- Provision of affordable goods and services: The development of a consumption model based on access over ownership can contribute to reduce the cost of goods and to provide affordable services such as transport and accommodation sectors. In addition, the use of internet platform and the peer-to-peer review can also contribute to reduce the searching costs and to increase the overall savings (McLaren and Agyeman, 2015; Stephany, 2015)

- Social impacts:

○ To reduce the gender gap: By providing more flexible working options the sharing economy can contribute to reduce the gender gap bypassing the potential barriers characterising the formal work structures (ICF, 2018; Schoenbaum, 2018). 
- To increase social bonding, collaboration and networking: Sharing one's possession with others is generally perceived as a pro-social behaviour contributing to improve solidarity and sense of community (Prothero et al., 2011). Most of the sharing activities, mainly based on solidarity and trust (see for example car-sharing and Couchsurfing), are also supposed to be able to generate social connection, intrapersonal relationships and networking (Bauwens, 2005; Belk, 2010; Benkler, 2017).

o To change the traditional form of sharing: The use of internet platform and the peer-to-peer review is contributing to extend the sharing activities from family and friends to people who do not know each other (Schor, 2014).

- To reduce the existing barriers between communities of society: The sharing activities taking place across communities of society can contribute to reduce social disparities by increasing trust and the sense of belonging to society (Benkler, 2017; Fitzmaurice et al., 2016).

- To increase democracy: The use of internet platforms is contributing to generate e-democracy and to increase socio-political participation (Praharaj et al., 2017).

- Environmental impacts: Sharing economy has been framed as a sustainable alternative to the consumption model based on the private ownership of resources. Based on the use of the hidden capacity of "shareable goods", defined by Benkler (2004) as goods that are not used by the owner for all the time, the sharing economy has the potential to improve the environmental standards by reducing pollution and consumption. The main environmental impacts can be summarised as:

○ To reduce the energy, the material demand and the generation of pollution and waste: The development of a consumption model based on collaborative consumption, swapping and reuse can contribute to reduce the overall production of goods, the related pollution and the generation of waste (Schor and Wengronowitz, 2017)

○ To reduce transport-related emissions: The development of a business model based on local proximity and community can contribute to reduce the transportrelated emissions. In addition, the implementation of a car-sharing system can reduce the consumption of fuel and the material and energy demand for the production of additional cars (Chen and Kockelman, 2015; Nijland and Van Meerkerk, 2015).

- To promote sustainable development by encouraging reduced and "greener" forms of consumption and transportation (Botsman and Rogers, 2010)

The possible impacts reported above are clearly linked with some of the SDGs adopted by the UN Member States in 2015. By including 17 goals and 169 targets, the SDG aim to promote socio-economic prosperity while protecting the environment. Ranging between end of poverty, sustainable development, equality, peace and wellbeing, the SDGs aim to set the political agenda for the next 15 years. However, the achievement of the interrelated objectives and the multidimensional framework of the SDGs constitute an important challenge calling for a global collaboration between governments, business activities and civil society. The sharing economy, based on the characteristics reported above, could provide a substantial contribution to the achievement of some of the goals of the Sustainable Development framework. In particular, the potential impacts generated in economic, socio and environmental terms could generate benefits across different of the goals established by UN. In table 2 some of the main relationships existing between SDGs and sharing economy are identified.

Table 2. SDG and expected benefits of sharing activities 


\begin{tabular}{|c|c|}
\hline SDGs & Sharing economy - Expected benefits \\
\hline Goal 1. & Sharing economy has been framed as model able to increase \\
\hline No poverty & $\begin{array}{l}\text { income opportunities, redistribution and wealth. Based on the use } \\
\text { of internet platforms, peer-to-peer exchange and trade outside the } \\
\text { traditional market systems, the sharing economy has been defined } \\
\text { as a structure to empower individuals and to promote the } \\
\text { development of micro-entrepreneurs. The economic and financial } \\
\text { opportunities provided by sharing activities can also contribute to } \\
\text { reduce poverty both between and within countries (Botsman and } \\
\text { Rogers, 2010; Sacks, 2011; Stephany, 2015). }\end{array}$ \\
\hline
\end{tabular}

Goal 5.

Gender equality

Goal 8.

Decent work and economic growth

Goal 9.

Industry, innovation and infrastructure

Goal 10.

Reduce inequality

Goal 11.

Sustainable city and communities
The possibility to generated income from the use of underutilised assets and the provision of services taking place outside the market system, can provide business opportunities for segments of population often excluded from the traditional job markets (ICF, 2018; Schoenbaum, 2018).

Based on the idea of freelance work and flexible employment opportunities, the sharing economy has been framed as a business model able to reduce the working constraints and to increase the opportunities for self-employment and independent contractors. The development of innovative business models alongside the persistence of the traditional market system is also considered as a structure able to increase income generation and growth (Horpedahl, 2015).

Innovation and technology are important factors of development. The recent expansion of internet connection, personal computers and mobile phone largely contributed to extend the sharing economy both in developed and developing countries. The use of sharing platform and the possibility to benefit from the sharing activities can contribute to expand the diffusion of information technologies, mobile phones and personal computer devices (Belk, 2014; Parente et al., 2018)

By providing opportunities for economic growth, innovative business models and employment opportunities, the sharing economy has been framed as a model contributing to reduce the socio-economic inequalities both between and within countries (Hamari et al., 2016; Kenney and Zysman, 2016).

The development of activities based on sharing, local provision and proximality, can be functional to increase the socio-environmental sustainability of the urban environment. Within this context, sharing economy has been described as model able to increase personal relationships, sustainability and trust. In addition, the consumption model based on the use, rather than ownerships, can contribute to reduce the environmental impacts of waste generation, production and consumption particularly in urban environment (Prothero et al., 2011; Fitzmaurice, et al., 2016). 
Goal 12.

Responsible production and consumption

Goal 13.

Climate action
Environmentally friendly claims are reported by most of the companies involved in sharing activities. The idea of reducing production and to disrupt the unsustainable practice of hyperconsumption are considered as some of the main features characterizing the sharing activities (Martin, 2016).

As reported above, sharing economy can contribute to reduce the environmental impacts of production and consumption. By providing consumers with the opportunity to use the excess capacity embedded into "shareable goods", the sharing economy can contribute to optimize the use of assets and to reduce the pollution related to good production, consumption and displacement (Acquier et al., 2017; Heinrichs, 2013).

\section{Sharing economy: risks and constraints}

Despite of the rapid worldwide expansion, the sharing economy is a relatively new phenomenon and we must be alert to the possible risk and constraints. Alongside the potential benefits, the lack of regulations and the large variety of business models recently developed within the framework of sharing can generated unexpected effects across different dimensions of the socio-economic and environmental systems. In recent years, academic literature has been discussing the discrepancies existing between the expected benefits of sharing and the possible risks related to applications. Martin (2016), Laurell and Sandstrom (2017) and Murillo (2017), for example, highlighted the existing contradiction between the idea of collaborative economy and the development of for-profit activities based on the use of the sharing platforms. Studies conducted by Eckhardt and Bardhi (2015), Barnes and Mattsson (2017) and Cansoy and Schor (2017), in addition, suggest that sharing activities play a minor role in the creation of community bonds and collaborations and that the racial disparities have not been reduced by the development of alternative business models. Environmental concerns have also been raised in relation to the increasing consumption and demand potentially generated by the higher affordability of assets (Mangiaracina et al. 2015, Parguel et al., 2017, Demailly and Novel 2014). The present structure of the sharing economy has the risk to generate effects going in a direction that is opposite to that established in the Sustainable Development Goals. In the following table (Table 3) an overview of the main contradictions existing between the possible negative impacts of the sharing activities is reported in the relation to the SDG reported in Table 2.

Table 3. SDG and risks of sharing economy practices

\begin{tabular}{ll}
\hline SDGs & Sharing economy - Expected benefits \\
\hline Goal 1. & Sharing economy can contribute to increase business activities, \\
income generation and growth. However, the benefits of sharing \\
can be concentrated in the hands of few, as demonstrated by the \\
creation large monopolies as Kickstarter, Uber, Etsy and Airbnb. \\
The economies of scale and the network externalities characterising \\
the use of the internet platform is presently reducing the market of \\
small and local enterprise, with consequent impacts on income \\
generation and redistribution. In addition, the lack of clear \\
regulation on national and international taxation can contribute to \\
increasing the accumulation of financial capital and to reduce the
\end{tabular}


public resources generally used to reduce inequalities and social disparities (Murillo et al., 2017; Kasprowicz, 2016).

Goal 5.

Gender equality

Goal 8.

Decent work and economic growth

\section{Goal 9.}

Industry, innovation and infrastructure

Goal 10.

Reduce inequality

Goal 11.

Sustainable city and communities
The development of business models based on the use of spare time and resources could increase the workload of the female population in a context where family-care related activities and activities taking place at home (such as Airbnb or Couchsurfing) are not considered by national accountability. In addition, some studies published for example by Edelman and Luca (2014), Cansoy and Schor (2017), Ge et al., (2016) highlight that racial disparities have not been decreased by the development of sharing activities. On the contrary, Afro-American Airbnb and Afro-American Uber drivers resulted to be discriminated in terms of less guests and longer waiting time and cancellations.

Based on the idea of freelance work and flexible employment opportunities, the sharing economy has been framed as a business model able to reduce the working constraints and to increase the opportunities for self-employment and independent contractors. Lack of pension and insurance, together with income instability and insecurity are however some of the main side effects generated by the working structure proposed by the sharing activities. At the present stage, the lack of proper regulations has generated working conditions generally classified not as decent as those characterising the traditional working market (Carboni, 2016).

The lack of clear international regulations around the storage and management of the personal information collected through the platforms can generate privacy-related issues. In addition, the large availability of information related to consumer preferences can be used by companies to target advertising tailored promotions.

At the present stage, the benefits of the sharing activities are not universally inclusive, on the contrary they tend to concentrate on certain groups of individuals. According to Stein (2015), for example the additional revenue generated by sharing activities mainly benefits people with a middle or upper-income level and exclude the low-income categories, with limited goods to share. In addition, the countryside or the remote areas result to have a reduce opportunity to share due to the lack of internet coverage and low density of sharing activities. In addition, the difficulties that a relevant percentage of the world population is experiencing in using the information technologies (for income, cultural and aging constraints) can contribute to generate an undemocratic system of asset provision.

As reported above, the use of sharing activities does not seem to provide a major contribution in the creation of social bonds and collaboration. In addition, the increased affordability of goods and services and the creation of new markets can expand the volume of 
commerce with consequent impacts on hyper-consumption, waste generation and pollution (Demailly and Novel 2014; Acquier et al., 2017)

Goal 12.

Responsible production and consumption

Goal 13.

Climate action
Environmentally friendly claims are reported by most of the companies involved in sharing activities. However, the marketrelated structure and the for-profit dominated logic that characterises most of the sharing activity generally contribute to expand the volume of commerce and to increase the pressure on environment (Martin, 2016).

At the present stage, no clear evidence exists around the reduction of energy and material demand. On the contrary, the increasing affordability of goods and services and the expansion of market activity contribute to increase the consumption of natural resources together with the production of pollution and waste. In addition, the short-term and temporary use of the goods available in a sharing context, generally lead to a lack of caring attitude and increase the turnover of the assets available in the market (Bocker and Meelen, 2017; Wilhelms et al., 2017).

In addition to the possible risks reported above, the developing countries are also experiencing a set of constraints such as lack of assets and skills, lack of regulations and norms, inadequate technologies (such as internet connection or electronic payment systems) and socio-cultural disparities. All these elements, together with the negative impacts reported in Table 2, constitute a real barrier to the contribution that the sharing activities could generate on the implementation of the SDG. In addition, large varieties of socio-economic and environmental conditions that characterize the vast panorama of developing countries makes it difficult to identify common policies able to support a sustainable implementation of sharing practices. Up to now a very limited number of researches have been specifically oriented to examine the sharing economy a low-income contexts and further analysis would be needed to investigate the possible impacts on developing trends (Retamal and Dominish, 2017).

\section{Conclusion}

Sharing economy is a worldwide phenomenon. Based on the use of internet platforms and on the access over the ownerships, the sharing economy is contributing to the development of alternative business models by introducing new way of connectivity and collaboration among people. According to this structure, the sharing economy has been generally framed as a possible solution to the negative impacts generated by the traditional market system. By promoting a more efficient and temporary use of resources, the sharing economy could potentially contribute to address some of the socio-economic and environmental objectives reported in the SDGs. Despite of these premises, however, the present structure of the sharing system involves large risks and constraints potentially able to generate inequalities, poverty and conflicts. As reported above, the lack of clear regulations and the large variety of activities included under the umbrella of sharing, could provide the base for a business model more unsustainable than the present one. In such a complex, diverse and worldwide extended phenomenon, the balance of risks and opportunities is not an 
easy task. The implementation of specific policies, however, could contribute to improving the sharing practices and to align the sharing economy to the objective of the SDGs. Some of the most urgent interventions are related to the following areas: $i$ ) to develop national and international regulations related to sharing practices, working conditions and taxation; ii) to support and consider the potential development of self-regulation, such as worker platforms for minimum wages or collaborative provisions among business activities; iii) to promote inclusion through increasing internet accessibility and literacy; $i v$ ) to create a market and regulatory environment for the development of small and independent business activities and to break-down the power of large monopolies; $v$ ) to develop programmes of education to sensitise people around social and environmental problems related to discrimination, disparities and hyper-consumption. These elements, among others, could contribute to shape and expand the sharing economy in respect to the individual and communities that are the constituting parts of the sharing philosophy. The potential benefits and risks related to the rapid expansion of this worldwide phenomenon should also be investigated by specific research oriented to investigate the possible impacts both in developed and developing countries.

\section{Cross-references}

Socio-economic innovation; information technologies

\section{References}

Acquier, A., Daudigeos, T., Pinkse, J., 2017. Promises and paradoxes of the sharing economy: An organizing framework. Technological Forecasting and Social Change, 125, pp. 1-10.

Barnes, S.J., Mattsson, F., 2017. Building tribal communities in the collaborative economy: an innovation framework. Prometheus, 34(2), pp. 95-113

Bauwens, M., 2005. The political economy of peer production. CTheory. Available at: http://www.ctheory.net/articles.aspx?id=499.

Belk, R., 2010. Sharing. Journal of Consumer Research, 36(5), pp. 715-734

Belk, R., 2014. You are what you can access: Sharing and collaborative consumption online. Journal of Business Research, 67(8), pp. 1595-1600.

Benkler, Y., 2004. Sharing Nicely: On Shareable Goods and the Emergence of Sharing as a Modality of Economic Production. Yale Law Journal 273

Benkler, Y., 2017. Peer production, the commons, and the future of the firm, Strategy. Organ, 15(2), pp. 264-274

Bocker, L., Meelen, T., 2017. Sharing for people, planet or profit? Analysing motivations for intended sharing economy participation. Environ. Innov. Soc. Trans., 23, pp. 28-39

Botsman, R., Rogers, R., 2010. What's mine is yours. In: Collaborative Consumption is Changing the Way We Live. Harper Business

Cansoy, M., Schor, J.B., 2017. Who Gets to Share in the Sharing Economy: Racial Discrimination on Airbnb. Working paper, Boston College

Carboni, M., 2016. A new class of worker for the sharing economy. Richmond J. Law Technol., 22(4), pp. 1

Chen, T.D., Kockelman, K.M., 2015. Carsharing's life-cycle impacts on energy use and greenhouse gas emissions. Paper Presented at the $94^{\text {th }}$ Annual Meeting of the Transportation Research Board, January 2015 
Dalberg, 2016. Digital sharing for global growth: Sharing resources, building economies. Dalberg Global Development Advisers. Retrieved from https://www.digitalsharingeconomy.com/

Demailly, D., Novel, A.S., 2014. The Sharing Economy: Make it Sustainable. IDDRI, Paris Eckhardt, G.M., Bardhi, F., 2015. The sharing economy isn't about sharing at all. Harv. Bus. Rev. Available at: https://hbr.org/2015/01/the-sharing-economy-isnt-about-sharing-at-all

Edelman, B.G., Luca, M., 2014. Digital discrimination: the case of Airbnb.com. Harvard Business School Working Paper, No. 14-054

Fitzmaurice, C., Ladegaard, I., Attwood-Charles, W., Carfagna, L., Cansoy, M., Schor, J., Wengronowitz, R., 2016. Domesticating the market: Moral exchange and the sharing economy, unpublished paper Boston College, http://www.bc.edu/content/dam/files/schools/cas_sites/sociology/pdf/MoralMarkets.pdf

Frenken, K., Schor, J., 2017. Putting the sharing economy into perspective. Environmental Innovation and Societal Transitions, 23, pp. 3-10

Ge, Y., Knittel, G.R., MacKenzie, D., Zoepf, S., 2016. Racial and gender discrimination in transportation network companies. NBER Working Paper No. 22776

Hamari, J., Sjoklint, M., Ukkonen, A., 2016. The sharing economy: why people participate in collaborative consumption. J. Assoc. Inf. Sci. Technol., 67, pp. 2047-2059

Heinrichs, H., 2013. Sharing Economy: A Potential New Pathway to Sustainability. Gaia, 22, pp. $228-231$

Horpedahl, J., 2015. Ideology Uber Alles. Economics bloggers on Uber, Lyft and other transportation network companies. Econ. J. Watch, 12(3), pp. 360-374

IFC, 2018. Driving Toward Equality: Women, Ride-Hailing and the Sharing Economy. Available at:

https://www.ifc.org/wps/wcm/connect/topics_ext_content/ifc_external_corporate_site/ge nder+at+ifc/drivingtowardequality

Kasprowicz, T., 2016. The emergence and development of a sharing economy. Liberte! Mag. Available at: http://4liberty.eu/review-5-the-emergence-and-development-of-a-sharingeconomy/

Kenney, M., Zysman, J., 2016. The rise of the platform economy. Issues Sci. Technol., 32, pp. 61

Laurell, C., Sandstrom, C., 2017. The sharing economy in social media: Analysing tensions between market and non-market logics. Technological Forecasting and Social Change, 125 , pp. 58-65

Mangiaracina, R., Marchet, G., Perotti, S., Tumino, A., 2015. A review of the environmental implications of B2C e-commerce: a logistics perspective. Int. J. Phys. Distrib. Logist. Manag., 45(6), pp. 565-591

Martin, C.J., 2016. The sharing economy: A pathway to sustainability or a nightmarish form of neoliberal capitalism? Ecological Economics, 121, pp. 149-159

Matzler, K., Veider, V., Kathan, W., 2015. Apting to the sharing economy. MIT Sloan Management Review, 56, pp. 270-277

McLaren, F., Agyeman, J., 2015. Sharing Cities: A Case for Truly Smart and Sustainable Cities. MIT Press

Mohlmann, M., 2015. Collaborative consumption: determinants of satisfaction and the likelihood of using a sharing economy option again. J. Consum. Behav, 14, pp. 193-207

Munoz, P., Cohen, B., 2017. Mapping out the sharing economy: A configurational approach to sharing business modelling. Technological Forecasting and Social Change, 125, pp. $21-37$ 
Murillo, D., Buckland, H., Val, E., 2017. When the sharing economy becomes neoliberalism on steroids: Unravelling the controversies. Technological Forecasting and Social Change, 125, pp. 66-76

Nijland, H., Van Meerkerk, J., Hoen, A., 2015. Mobility and environmental impacts of carsharing in The Netherlands, PBL Note 1842, July, www.pbl.nl.

Parente, R.C., Geleilate, J.-M.G., Rong, K., 2018. The Sharing Economy Globalization Phenomenon: A Research Agenda. Journal of International Management, 24(1), pp. 5264

Parguel, B., Lunardo, R., Benoit-Moreau, F., 2017. Sustainability of the sharing economy in question: when second-hand peer-to-peer platforms stimulate indulgent consumption. Technol. Forecast. Soc. Change, 125, pp. 48-57

Praharaj, S., Hoon, H., Hawden, H.S., 2017. Innovative Civic Engagement and Digital Urban Infrastructure: Lessons from 100 Smart Cities Mission in India. Procedia Engineering, 180, pp.1423-1432

Prothero, A., Dobscha, S., Freund, J., Kilbourne, W.E., Luchs, M.G., Ozanne, L.C., Thogersen, J., 2011. Sustainable consumption: opportunities for consumer research and public policy. Journal Public Policy Mark, 30(1), pp. 31-38

Retamal, M., Dominish, E., 2017. The Sharing Economy in Developing countries. Prepared by the Institute for Sustainable Futures at the University of Technology Sydney (UTS) for Tearfund UK.

Sacks, D., 2011. The Sharing Economy. Fast Company. Available at: http://www.fastcompany.com/magazine/155/the-sharingeconomy.htm

Schoenbaum, N., 2018. Intimacy and Equality in the Sharing Economy. In: Davidson N, Infranca J, Finch M (Eds.) The Cambridge Handbook of the Law of the Sharing Economy

Schor, J., 2014. Debating in sharing economy. In: A Great Transition Initiative Essay. Available at: http://greattransition.org/publication/debating-the-sharing-economy

Shor, J.B., Wengronowitz, R., 2017 The new sharing economy: enacting the eco-habitus. In: Brown, H., Cohen, M., Vergragt, P., (Eds.), Sustainable Consumption and Social Change. Routledge, London, 2017

Stein, J., 2015. Baby, You Can drive My Car and Stay in My Guest Room. And Do My Errands. And Rent My Stuff. My Wild Ride Through the New On-demand Economy. TIME, pp. 32-40

Stephany, A., 2015. The Business of Sharing - Making it in the New Sharing Economy. Palgrave MacMillan, New York, NY

Sundararajan, A., 2016. The Sharing Economy: The End of Employment and the Rise of Crowd-Based Capitalism. MIT Press

UN - Sustainable Development Goals: https://sustainabledevelopment.un.org/?menu=1300

Wilhelms, M.P., Henkel, S., Falk, T., 2017. To earn is not enough: a means-end analysis to uncover peer-providers' participation motives in peer-to-peer carsharing. Technol.

Forecast. Soc. Change, 125, pp. 38-47 